\title{
Online drug shortage registry "limited" in application
}

A $\mathrm{n}$ online registry of current and impending drug shortages has been launched as part of a bid to help physicians and pharmacists plan for pharmaceutical shortfalls.

Health practitioners can now access national data on shortages of generic and brand-name drugs volunteered by drugmakers at two existing websites that previously reported strictly on regional supply disruptions: the Saskatchewan Drug Information Service (http://druginfo .usask.ca/healthcare_professional/drug shortages.php) and Vendredi PM (http ://vendredipm.wordpress.com). The database will include the names and dosages of drugs in short supply, as well as the reasons for the disruptions and estimates of when supply problems will be resolved.

The registry will improve awareness of drug shortages, President Russell Williams writes on behalf of Canada's Research-Based Pharmaceutical Companies (Rx\&D). "By having manufacturers report shortages in this way, we now have a reporting system that allows innovative pharmaceutical companies to report earlier compared to what existed before. This is a system that can span entire geographies without needing to validate if the issue is local or national."

"By having manufacturers report and confirm shortages, we know at the earliest possible moment that a shortage is either imminent or is real because the manufacturer and its wholesale and distribution partners know their supply on-hand, they know what patient demand is, and they monitor closely how supply and demand changes over time. They also know if, for example, a supplier of a raw ingredient or other ingredient is experiencing a global shortage of their own," Williams adds.

But the makeshift registry is just a "temporary step" toward a truly comprehensive drug shortage monitoring system as it only captures supply problems flagged by drug companies and

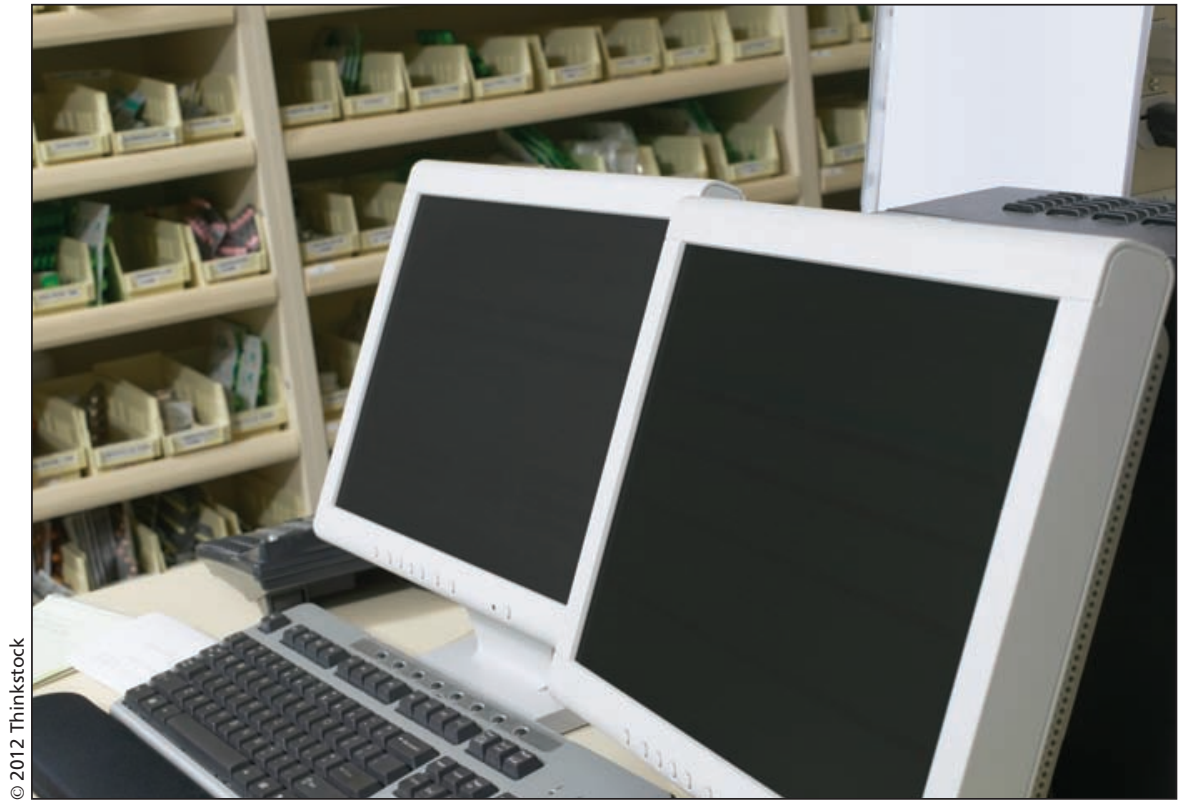

The developers of a new online registry for drug shortages say that physicians and pharmacists will be just a click away from determining whether there is a shortfall for a pharmaceutical.

doesn't provide information about therapeutic alternatives, says Myrella Roy, executive director of the Canadian Society of Hospital Pharmacists, a partner in the initiative along with the Canadian Medical Association, the Canadian Generic Pharmaceutical Association (CGPA), the Canadian Pharmacists Association ( $\mathrm{CPhA}$ ), BIOTECanada and Rx\&D.

"The major hurdle of getting from here to there is going to be funding," explains Roy. "We're hoping that by the end of 2012 we'll at least have a unique, bilingual drug shortage monitoring system [rather than hosting the information on the regional sites] so physicians and pharmacists will have a single portal they can go to for fairly comprehensive information."

Drug manufacturers could previously opt to report supply disruptions to Health Canada but that information was rarely disseminated in time to enable frontline workers to plan for shortages. As a result, hospitals and physicians have had to delay or ration potentially life-saving treatments, and pharmacists say patient care has suffered (www.cmaj.ca/lookup/doi/10 .1503/cmaj.109-3904).

"Previously," Williams writes, "where reporting existed (and there were very few examples in Canada), it was either geographically limited or tied to individual institutions of care or pharmacies. As a result, reporting tended to come from numerous different sources, none of whom have the resources to confirm whether what they were experiencing was indeed 'a shortage' or possibly a short-lived case of not having a medicine 'in stock'. These situations of 'internal reporting' may still exist, as all institutions or places of business tend to know what supply they need to meet their normal expected demand. For example, in a hospital or pharmacy setting, if a pharmacy could not source a particular drug, they might call colleagues in other parts of the city to see if they too were experiencing a shortage. This obviously takes time and may not yield a complete picture of the supply of a particular medicine in the whole city, province or country." 
A $2010 \mathrm{CPhA}$ survey of pharmacists revealed that $81 \%$ had trouble finding medications to fill a prescription during their last shift, while $94 \%$ had problems locating at least one drug in the previous week. Some reported difficulties obtaining products for well over 200 prescriptions and $70 \%$ believed the shortages were affecting patients' health (www.pharmacists.ca/cpha-ca/assets /File/cpha-on-the-issues/DrugShortages Report.pdf).

Earlier notification of impending shortages through the new nation-wide registry will give health professionals more breathing room in which to make alternate treatment plans and secure substitutes for scarce drugs, thereby mitigating the direct impact of supply disruptions on patient care, says Jeff Connell, public affairs director for the CGPA.

Roy says the registry will save time and resources for practitioners who might otherwise have had to track down information about shortages on their own. Pharmacists reported in the $\mathrm{CPhA}$ survey that they spent an average 30 minutes per shift dealing with drug shortages and tracking down such information.

But the usefulness of the new reporting scheme is limited by the fact that manufacturer participation is entirely voluntary and currently restricted to members of Rx\&D and the CGPA. As a consequence, "there may be gaps in the data" and "there is no warranty, representation or guarantee with respect to the accuracy, timeliness or completeness of this information," according to Saskatchewan Drug Information Services (www.druginfo.usask.ca/health care_professional/canadian_drug_short ages.php).

Gaps in the drug companies' data could be bridged by providing a mechanism for physicians and pharmacists to report suspected shortages directly to the registry for further investigation, Roy says. "Without the possibility of notification from health care practitioners about suspected drug shortages from non-member companies, the drug shortage data is incomplete."

In the United States, physicians or pharmacists encountering a shortage can inform the American Society of Health System Pharmacists, which then contacts manufacturers to confirm the shortage and obtains an estimated date as to when the drug might be available.

But Connell contends health practitioners have too narrow a view of the pharmaceutical supply chain to provide valuable information to a national drug shortage monitoring system. "In particular, I'm not sure how a physician could know whether there's a drug shortage or not, other than being told by manufacturers or a pharmacy."

And Roy notes that there is a "possibility of [physicians and pharmacists] misreporting drug shortages" because there could be "any number of reasons why stock doesn't reach the user," including "the delivery truck getting stuck in the snow." But she contends such cases may nevertheless be worthy of investigation and could easily be validated before being posted to the public registry.

A further limitation of the newly created registry is that it doesn't provide information on therapeutic alternatives to drugs in short supply - a feature most pharmacists cite as one of the "preferred elements" of a comprehensive drug shortage monitoring system, Roy says. "Currently, the reports from the drug industry don't provide that information for understandable reasons. Manufacturers are not in a good position to make suggestions to that effect because they may not know the potential alternatives as well as a healthcare professional, but also for reasons of competition."

"Now that the information about what shortages exist is available publicly, the next piece of information that's going to be critical for pharmacists and physicians is a recommendation about what else they can use," Roy adds.

Without that information, "basically every single physician and pharmacist tries to research and determine the best alternative on their own, and you have thousands of people doing the same work at a cost to the system."

Although work to develop a more robust system is underway, federal funding will be necessary to actually implement and sustain such a system, Roy says. "It will be costly to have staff that will be able to do the validation of practitioner-reported shortages or pharmacists who can research and suggest alternatives to the drugs that are in short supply. At the national level, we're probably looking at the equivalent of three full-time staff, potentially more. We don't have the financial resources to support that."

But Health Canada has repeatedly stated that it will not provide funding to develop and maintain a single national drug shortage monitoring system, which makes the future of any registry uncertain, Roy says. "This was meant as a debt-free measure, but we haven't talked about what if."

Other partners in the initiative were unavailable for comment. - Lauren Vogel, CMAJ

CMAJ 2012. DOI:10.1503/cmaj.109-4100 